\title{
Mechanisms of exertional dyspnoea in pulmonary veno-occlusive disease with EIF2AK4 mutations
}

\begin{abstract}
To the Editor:
Dyspnoea curtails daily-living activities in patients with pulmonary veno-occlusive disease (PVOD) $[1,2]$ and pulmonary arterial hypertension $(\mathrm{PAH})$ [3-5]. It is a common clinical observation that PVOD patients may experience greater dyspnoea than PAH patients during daily activities [1, 2]. However, this clinical feature and its putative underlying mechanisms have not yet been explored. Cardiopulmonary exercise testing (CPET) is well suited for understanding mechanisms underlying dyspnoea during exercise both in research and clinical settings $[4,5]$. In the present study, we hypothesised that the perceived clinical difference between PVOD and PAH regarding exertional dyspnoea would be reflected by a different physiological response to CPET. Building on recent advances obtained with CPET in PAH patients [4], we set out to evaluate the relationship between exertional dyspnoea and the physiological response to CPET in eight PVOD patients presenting with recessive mutations in EIF2AK4, compared with 16 idiopathic or heritable PAH patients.
\end{abstract}

We studied eight clinically stable patients referred to the French Reference Center for Pulmonary Hypertension (Le Kremlin-Bicêtre, France) for management of PAH [6, 7]. Using whole-exome sequencing, we detected recessive mutations in the major gene linked to PVOD development, EIF2AK4 (also called GCN2), that co-segregated with PVOD in eight patients studied, as recently described [8]. 16 clinically stable patients with diagnosed idiopathic or heritable PAH [9] and without other concomitant diseases were also evaluated.

Pulmonary function tests, cycle ergometer symptom-limited incremental CPET, and measurements at rest and at peak exercise of arterial oxygen tension $\left(\mathrm{PaO}_{2}\right)$ and arterial carbon dioxide tension $\left(\mathrm{PaCO}_{2}\right)$, the physiological dead space $(V \mathrm{D}) /$ tidal volume $(V \mathrm{~T})$ ratio, and the alveolar-arterial oxygen tension gradient $\left(P \mathrm{~A}-\mathrm{aO}_{2}\right)$ and arterial-end-tidal carbon dioxide tension gradient $\left(P \mathrm{a}-\mathrm{ETCO}_{2}\right)$ were evaluated as previously described [4]. The intensity of dyspnoea was rated using the modified 10-point Borg scale [10] at rest and at peak exercise.

Between-group comparisons during exercise were made using unpaired t-tests with a Bonferroni adjustment for repeated measurements. Statistically significant differences between New York Heart Association (NYHA) functional classes within each group and between groups were evaluated by the Chisquared test with the Yates correction. A p $<0.05$ level of statistical significance was used for all analyses.

PVOD and PAH patients were perfectly matched in terms of anthropometric characteristics and resting haemodynamics. Statistically significant differences were found between NYHA functional class II and III within each group and between groups (Chi-squared test $p=0.009$, Yates correction $p=0.03$ ): class I, no PVOD patients versus four PAH; class II, two PVOD patients versus $10 \mathrm{PAH}$; class III, six PVOD patients versus two $\mathrm{PAH}$.

No differences were found in pulmonary function variables between the two groups except for the diffusing capacity of the lung for carbon monoxide (DLCO), which was significantly reduced in PVOD compared with PAH $(32 \pm 5 \%$ versus $76 \pm 19 \%$ pred, respectively).

The physiological responses to CPET are shown in figure 1. Dyspnoea intensity (Borg score) was higher at peak exercise in PVOD patients than $\mathrm{PAH}(8.3 \pm 0.7$ versus $6.7 \pm 1.7$, respectively). The minute ventilation $\left(V^{\prime} \mathrm{E}\right)$ /carbon dioxide production $\left(V^{\prime} \mathrm{CO}_{2}\right)$ slope, a measure of ventilatory efficiency, was increased to a greater extent in PVOD patients than in PAH patients $(55 \pm 14$ versus $39 \pm 8$, respectively; $\mathrm{p}=0.01$ ). Compared with $\mathrm{PAH}$ subjects, $\mathrm{PaO}_{2}$ was significantly lower at rest $(73.9 \pm 8.7$ versus $86.3 \pm 10.4 \mathrm{mmHg}$, respectively; $\mathrm{p}=0.007)$ and at peak exercise in PVOD $(43.1 \pm 3.8$ versus $83.5 \pm 14.8 \mathrm{mmHg}$, respectively; $\mathrm{p}<0.00001) . \mathrm{PaCO}_{2}$ was also significantly lower at rest $(30.3 \pm 1.9$ versus $33.4 \pm 3.8 \mathrm{mmHg}$, respectively; $\mathrm{p}=0.02)$ and at peak exercise in PVOD compared with $\mathrm{PAH}(26.6 \pm 2.9$ versus $31.4 \pm 4.1 \mathrm{mmHg}$, respectively; $\mathrm{p}=0.01$ ), although the rest-to-peak difference in $\mathrm{PaCO}_{2}$ did not significantly differ between PVOD and PAH. $P \mathrm{~A}_{-} \mathrm{aO}_{2}$ at rest $(41 \pm 9$ versus $26 \pm 14 \mathrm{mmHg}$, respectively; $\mathrm{p}=0.006)$ and at peak exercise 
( $84 \pm 3$ versus $38 \pm 17 \mathrm{mmHg}$, respectively; $\mathrm{p}<0.00001$ ) was greater in PVOD compared with PAH. VD/VT was similar at rest between the groups $(0.54 \pm 0.06$ versus $0.49 \pm 0.11$, respectively; $\mathrm{p}=0.2)$ but higher at peak exercise in PVOD compared with PAH $(0.50 \pm 0.05$ versus $0.37 \pm 0.08$, respectively; $\mathrm{p}=0.001)$. Of note, $\mathrm{Pa}_{\mathrm{aTCO}}$, was similar at rest between the groups $(6.4 \pm 3.2$ versus $4.5 \pm 2.5 \mathrm{mmHg}$, respectively; $\mathrm{p}=0.2)$ but higher at peak exercise in PVOD compared with $\mathrm{PAH}(8.7 \pm 1.9$ versus $4.6 \pm 3.3 \mathrm{mmHg}$, respectively; $\mathrm{p}=0.003)$.

At anaerobic ventilatory threshold $(37 \pm 16$ versus $45 \pm 13 \mathrm{~W}$ for PVOD versus $\mathrm{PAH}$, respectively; $\mathrm{p}=0.2)$, $V^{\prime} \mathrm{O}_{2}$ was reduced to a greater extent in PVOD than in PAH $(26 \pm 9 \%$ versus $35 \pm 8 \%$ predicted, respectively; $\mathrm{p}=0.03)$, while $V^{\prime} \mathrm{E} / V^{\prime} \mathrm{CO}_{2}$ ratio $(51 \pm 8$ versus $37 \pm 6$, respectively; $\mathrm{p}=0.001)$ and $V^{\prime} \mathrm{E} / V^{\prime} \mathrm{CO}_{2}$ ratio $(54 \pm 7$ versus $40 \pm 7$, respectively; $\mathrm{p}=0.0007)$ were higher and $\mathrm{PETCO}_{2}$ lower $(23 \pm 4$ versus $31 \pm 5 \mathrm{mmHg}$, respectively; $\mathrm{p}=0.001$ ) in PVOD compared with $\mathrm{PAH}$.

The main findings of this study are as follows: 1) dyspnoea during daily-living activity (NYHA) and cycle exercise (Borg score) was greater in patients with PVOD compared with PAH; 2) ventilatory demand was significantly more elevated in PVOD than in PAH at any given work rate and $V^{\prime} \mathrm{O}_{2}$ during exercise; and 3) PVOD patients showed a greater gas exchange inefficiency and worse oxygen delivery/utilisation during exercise that probably contributed to the ventilatory abnormalities observed during exercise.

The PVOD patients we studied were well matched to the PAH patients in terms of anthropometric characteristics, resting haemodynamics and pulmonary function (except for DLCO). Nonetheless, PVOD patients reported greater chronic activity-related dyspnoea (NYHA) than PAH and were more likely to report dyspnoea as an exercise-limiting symptom at the end of CPET compared with their PAH counterparts. Dyspnoea intensity was higher at peak exercise in PVOD than in PAH, and this may be accounted for by the increased $V^{\prime}$ E achieved at any stage of exercise by PVOD compared with PAH (fig. 1).

Potential factors contributing to the greater exertional dyspnoea in PVOD patients are: 1) higher ventilatory demand; 2) increased vascular congestion/distension; and 3) a more altered dynamic ventilatory mechanics that would cause dyspnoea to increase at any given $V^{\prime}$ E.
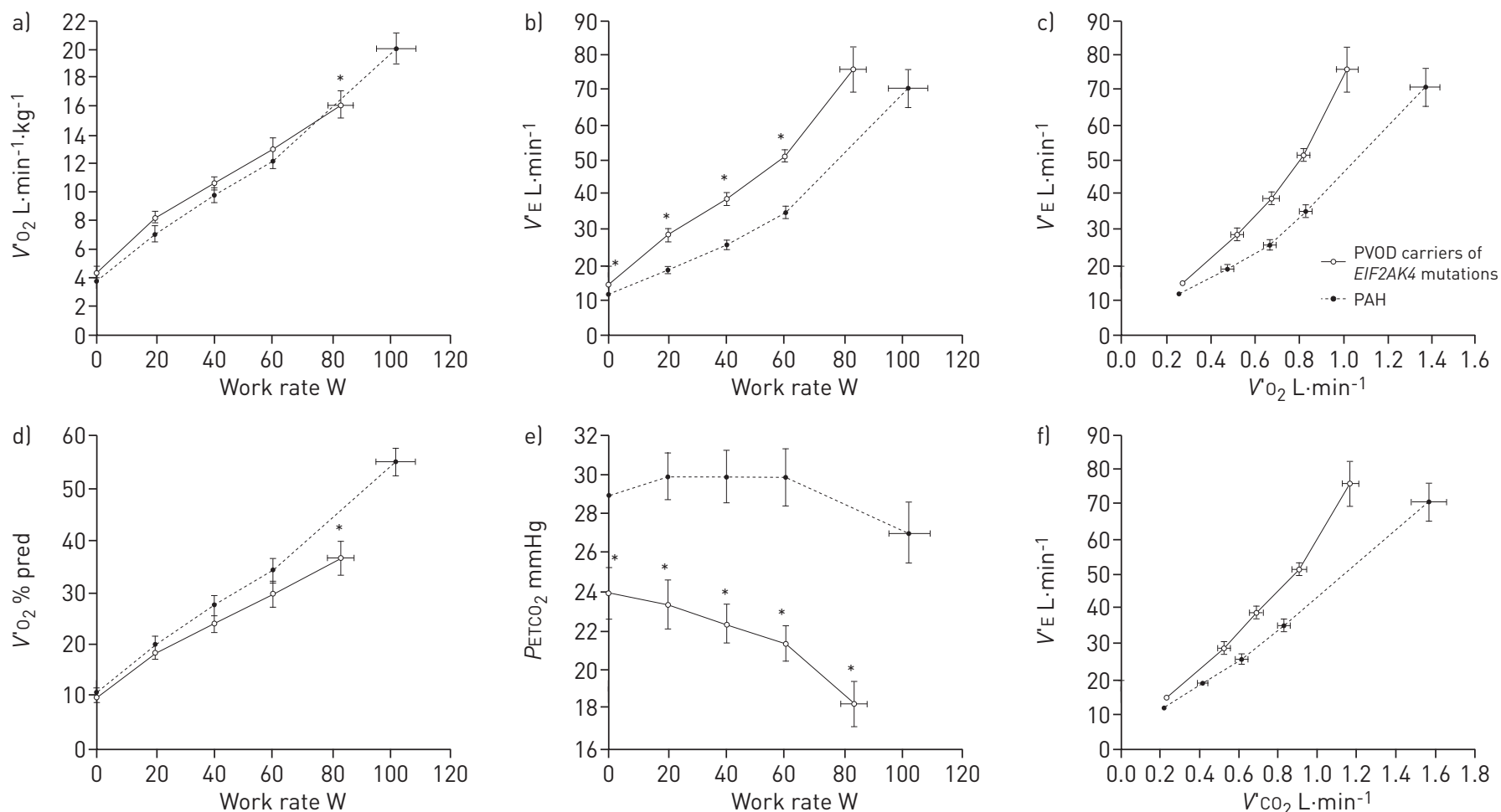

FIGURE 1 a) Oxygen uptake ( $\left.V^{\prime} \mathrm{O}_{2}\right)$ corrected for body weight and d) expressed as percentage of predicted normal value, b) minute ventilation ( $V^{\prime} \mathrm{E}$ ), and e) endtidal carbon dioxide tension $\left(\mathrm{PETCO}_{2}\right)$ are shown in response to increasing work rate during symptom-limited incremental cycle exercise in patients with

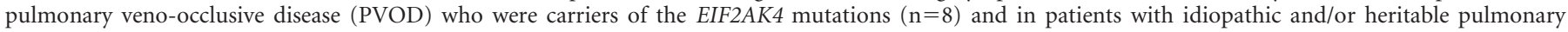
arterial hypertension ( $\mathrm{PAH})(\mathrm{n}=16) ; V^{\prime} \mathrm{E}$ is also shown in response to c) increasing $V^{\prime} \mathrm{O}_{2}$ and $\mathrm{f}$ ) increasing carbon dioxide production $\left(V^{\prime} \mathrm{CO} \mathrm{O}_{2}\right)$ during symptomlimited incremental cycle exercise in patients with PVOD carriers of the EIF2AK4 mutations $(\mathrm{n}=8)$ and in patients with PAH ( $\mathrm{n}=16)$. Data are presented as mean \pm SEM. Values are shown at rest, at 20,40 and $60 \mathrm{~W}$, and at peak exercise. ${ }^{*}: \mathrm{p}<0.05$ for PVOD versus PAH. 
The increased ventilatory demand to CPET in PVOD compared with PAH is a novel finding. Although similar at peak exercise, $V^{\prime} \mathrm{E}$ was significantly increased at any given submaximal work rate and $V^{\prime} \mathrm{O}_{2}$ throughout exercise in PVOD compared with $\mathrm{PAH}$ (fig. 1). Potential contributory factors include: 1) reduction of true alveolar-capillary membrane diffusing capacity; 2) increased ventilation/perfusion mismatching, reflecting reduced cardiac output or increased $V \mathrm{D} / V \mathrm{~T} ; 3$ ) early local metabolic acidosis, reflecting reduced oxygen delivery/utilisation or deconditioning; 4) a lower $\mathrm{PaCO}_{2}$ set-point; or 5) any combination of the above.

In accordance with the results of previous studies [1], PVOD patients showed a greater reduction in resting DLCO than PAH [11]. We can speculate that a severe reduction in DLCO may reflect a severe reduction of true alveolar-capillary membrane diffusing capacity in PVOD, as pointed out by several structural changes in lung microvasculature $[1,12]$. This may also explain why resting $\mathrm{PaO}_{2}$ was reduced and kept reducing during exercise, and $\mathrm{PA}_{\mathrm{A}} \mathrm{aO}_{2}$ widened during exercise to a greater extent in PVOD despite the same level of $V^{\prime}$ E achieved at peak.

Our study did not provide any insights in the adaptations of cardiac output during exercise in the two groups. However, oxygen pulse was lower in PVOD than in PAH at peak exercise, therefore raising the question of whether cardiac function could be more deranged in PVOD than in PAH. We cannot completely exclude this.

Compared with $\mathrm{PAH}$, PVOD showed increased $V^{\prime} \mathrm{E} / V^{\prime} \mathrm{CO}_{2}$ slope and ratio, a nonsignificant fall in $P \mathrm{aCO}_{2}$, a greater fall in $\mathrm{PaO}_{2}$ and a greater increase in $\mathrm{Pa}_{\mathrm{a}} \mathrm{ETCO}_{2}$ throughout exercise, which probably reflected increased ventilation/perfusion mismatch as a result of impaired ability to reduce a higher physiological dead space during exercise due to impaired pulmonary perfusion.

Earlier local metabolic acidosis may have also triggered an earlier rise in $V^{\prime} \mathrm{E}$ in PVOD patients compared with PAH. Anaerobic ventilatory thresholds, although reduced in both groups, did occur at a lower $V^{\prime} \mathrm{O}_{2}$ in PVOD than in PAH. A greater reduction of oxygen delivery/utilisation in PVOD patients than PAH cannot be entirely excluded.

The excessive $V^{\prime} \mathrm{E}$ observed in PVOD compared with PAH can be due to alveolar hyperventilation due to a decreased $\mathrm{PaCO}_{2}$ set point [13]. However, potential sources of a decreased $\mathrm{PaCO}_{2}$ set point were not elucidated in our study.

The potential contribution of increased vascular congestion/distension to exertional dyspnoea in PVOD via cardiopulmonary vagal reflexes was not explored in our study and deserves further investigation.

The contribution of altered dynamic ventilatory mechanics to the abnormal ventilatory response to exercise in PVOD seems unlikely given that resting spirometry (including the maximal flow-volume loop) and lung volumes were comparable between the two groups.

Activity-related dyspnoea represents a major challenge for both patients and caregivers [5]. This study is the first to examine the perceptual response to CPET in patients with PVOD who were carriers of EIF2AK4 mutations compared with $\mathrm{PAH}$ patients matched for resting haemodynamics and pulmonary function. The results showed that the increased ventilatory demand contributed to the greater dyspnoea intensity found in PVOD compared with PAH patients. The physiological and clinical implications of these findings are that CPET may help clinicians identify the potential mechanisms underpinning the greater dyspnoea observed in patients with PVOD.

0

@ERSpublications

A more deranged ventilatory response to CPET contributes to greater dyspnoea in PVOD patients than in PAH http://ow.ly/ze6zN

Pierantonio Laveneziana ${ }^{1,2,3,4,12}$, David Montani ${ }^{5,6,7,12}$, Peter Dorfmüller ${ }^{5,6}$, Barbara Girerd ${ }^{5,6,7}$, Olivier Sitbon ${ }^{5,6,7}$, Xavier Jaïs ${ }^{5,6,7}$, Laurent Savale ${ }^{5,6,7}$, Mélanie Eyries ${ }^{8,9,10}$, Florent Soubrier ${ }^{8,9,10}$, Thomas Similowski ${ }^{1,2,11}$, Gérald Simonneau ${ }^{5,6,7}$, Marc Humbert ${ }^{5,6,7}$ and Gilles Garcia ${ }^{4,5,6}$

${ }^{1}$ Sorbonne Universités, UPMC Univ. Paris 06, UMR_S 1158, Neurophysiologie Respiratoire Expérimentale et Clinique, Paris, France. ${ }^{2}$ INSERM, UMR_S 1158, Neurophysiologie Respiratoire Expérimentale et Clinique, Paris, France. ${ }^{3}$ AP-HP, Groupe Hospitalier Pitié-Salpêtrière Charles Foix, Service des Explorations Fonctionnelles de la Respiration, de l'Exercice et de la Dyspnée, Paris, France. ${ }^{4} \mathrm{AP}-\mathrm{HP}$, Hôpital Universitaire de Bicêtre, Service d'Explorations Fonctionnelles Respiratoires, Centre de Référence de l'Hypertension Pulmonaire Sévère, DHU TORINO “Thorax Innovation”, Le Kremlin-Bicêtre, France. ${ }^{5}$ Univ. Paris-Sud 11, Faculté de médecine, Le Kremlin-Bicêtre, France. ${ }^{6}$ INSERM U999, LabEx LERMIT, Centre Chirurgical Marie Lannelongue, Le Plessis-Robinson, France. ${ }^{7}$ AP-HP, Service de Pneumologie et Soins Intensifs Thoraciques, Centre de Référence de l'Hypertension Pulmonaire Sévère, DHU TORINO “Thorax Innovation”, Hôpital Universitaire de Bicêtre, Le Kremlin-Bicêtre, France. ${ }^{8}$ UMR_S 956, UPMC and INSERM, Paris, France. ${ }^{9}$ Genetics Dept, Hôpital Pitié-Salpêtrière, AP-HP, Paris, France. ${ }^{10}$ Institute for Cardiometabolism and Nutrition (ICAN), Paris, 
France. ${ }^{11} \mathrm{AP}-\mathrm{HP}$, Groupe Hospitalier Pitié-Salpêtrière Charles Foix, Service de Pneumologie et Réanimation Médicale, Paris, France. ${ }^{12}$ Both authors contributed equally.

Correspondence: Gilles Garcia, AP-HP, Hôpital Universitaire de Bicêtre, Service d'Explorations Fonctionnelles Respiratoires, Centre de Référence de l'Hypertension Pulmonaire Sévère, DHU TORINO "Thorax Innovation", 78 Rue du Général Leclerc, 94270, Le Kremlin-Bicêtre, France. E-mail: gilles.garcia@bct.aphp.fr

Received: March 212014 | Accepted after revision: June 282014 | First published online: Aug 202014

Conflict of interest: None declared.

Acknowledgements: Some of the results of this study have been previously reported in the form of an abstract for which P. Laveneziana was the recipient of the Young Investigator Award at the fifth World Symposium on Pulmonary Hypertension, which was held in Nice, France, from February 27 to March 1, 2013.

\section{References}

1 Montani D, Achouh L, Dorfmuller P, et al. Pulmonary veno-occlusive disease: clinical, functional, radiologic, and hemodynamic characteristics and outcome of 24 cases confirmed by histology. Medicine (Baltimore) 2008; 87: 220-233.

2 Montani D, Price LC, Dorfmuller P, et al. Pulmonary veno-occlusive disease. Eur Respir J 2009; 33: 189-200.

3 McLaughlin VV, Badesch DB, Delcroix M, et al. End points and clinical trial design in pulmonary arterial hypertension. J Am Coll Cardiol 2009; 54: Suppl., S97-S107.

4 Laveneziana P, Garcia G, Joureau B, et al. Dynamic respiratory mechanics and exertional dyspnoea in pulmonary arterial hypertension. Eur Respir J 2013; 41: 578-587.

5 Laviolette L, Laveneziana P. Dyspnoea: a multidimensional and multidisciplinary approach. Eur Respir J 2014; 43: $1750-1762$.

6 Badesch DB, Champion HC, Sanchez MA, et al. Diagnosis and assessment of pulmonary arterial hypertension. J Am Coll Cardiol 2009; 54: Suppl., S55-S66.

7 Galie N, Hoeper MM, Humbert M, et al. Guidelines for the diagnosis and treatment of pulmonary hypertension. Eur Respir J 2009; 34: 1219-1263.

8 Eyries M, Montani D, Girerd B, et al. EIF2AK4 mutations cause pulmonary veno-occlusive disease, a recessive form of pulmonary hypertension. Nat Genet 2014; 46: 65-69.

9 Simonneau G, Robbins IM, Beghetti M, et al. Updated clinical classification of pulmonary hypertension. J Am Coll Cardiol 2009; 54: Suppl., S43-S54.

10 Borg GA. Psychophysical bases of perceived exertion. Med Sci Sports Exerc 1982; 14: 377-381.

11 Trip P, Girerd B, Bogaard HJ, et al. Diffusion capacity and BMPR2 mutations in pulmonary arterial hypertension. Eur Respir J 2014; 43: 1195-1198.

12 Miura A, Akagi S, Nakamura K, et al. Different sizes of centrilobular ground-glass opacities in chest high-resolution computed tomography of patients with pulmonary veno-occlusive disease and patients with pulmonary capillary hemangiomatosis. Cardiovasc Pathol 2013; 22: 287-293.

13 Sun XG, Hansen JE, Oudiz RJ, et al. Exercise pathophysiology in patients with primary pulmonary hypertension. Circulation 2001; 104: 429-435.

\section{The concept of control in COPD: a new proposal for optimising therapy}

\section{To the Editor:}

Chronic obstructive pulmonary disease (COPD) is a very heterogeneous disease and therefore treatment should be individualised considering the different clinical characteristics and severity of each patient [1-3]. In an attempt to identify individuals with similar characteristics and response to treatment, a group of experts has defined the "clinical phenotypes" of COPD as those attributes of the disease alone or in combination that "describe differences between individuals with COPD in relation to parameters that have clinical significance (symptoms, exacerbations, response to treatment, rate of progression disease, or death)" [4]. Therefore, the clinical phenotype should be able to classify patients into subgroups with prognostic value and to determine the most appropriate therapy to achieve better results from a clinical standpoint.

However, even patients with similar clinical characteristics and degree of airflow obstruction may have a different expression of their disease or present with short-term changes in their state that may require changes in treatment. Therefore, the new concept of disease control, similar to the "control of asthma" concept should be added in the assessment of patients with COPD. But, what is control in COPD? 